\title{
High thermoelectric efficiency in lanthanum doped $\mathrm{Yb}_{14} \mathrm{MnSb}_{11}$
}

\author{
Eric S. Toberer, ${ }^{1}$ Shawna R. Brown, ${ }^{2}$ Teruyuki Ikeda, ${ }^{1}$ Susan M. Kauzlarich, ${ }^{2}$ and \\ G. Jeffrey Snyder, ${ }^{1, a)}$ \\ ${ }^{1}$ Materials Science, California Institute of Technology, 1200 California Blvd., Pasadena, California 91125, \\ USA \\ ${ }^{2}$ Department of Chemistry, University of California, One Shields Ave., Davis, California 95616, USA
}

(Received 23 June 2008; accepted 24 July 2008; published online 15 August 2008)

\begin{abstract}
Lanthanum doping of the high-temperature $p$-type thermoelectric material $\mathrm{Yb}_{14} \mathrm{MnSb}_{11}$ enhances the figure of merit $(z T)$ through carrier concentration tuning. This is achieved by substituting $\mathrm{La}^{3+}$ on the $\mathrm{Yb}^{2+}$ site to reduce the free hole concentration as expected from the change in valence. The high-temperature transport properties (Seebeck coefficient, electrical resistivity, Hall mobility, and thermal conductivity) of $\mathrm{Yb}_{13.6} \mathrm{La}_{0.4} \mathrm{MnSb}_{11}$ are explained by the change in carrier concentration using a simple rigid parabolic band model, similar to that found in $\mathrm{Yb}_{14} \mathrm{Mn}_{1-x} \mathrm{Al}_{x} \mathrm{Sb}_{11}$. Together, use of these two dopant sites enables the partial decoupling of electronic and structural properties in $\mathrm{Yb}_{14} \mathrm{MnSb}_{11}$-based materials. (C) 2008 American Institute of Physics. [DOI: 10.1063/1.2970089]
\end{abstract}

Thermoelectric generators have the potential to provide clean, reliable electricity through waste heat recovery or cogeneration. As current generator efficiencies are insufficient for widespread application, there is an interest in the development of improved thermoelectric materials. Generator efficiency depends on both the Carnot efficiency and the material thermoelectric figure of merit $\left(z T=\alpha^{2} T / \rho \kappa\right.$, where $T$ is absolute temperature). Material improvements have been challenging because of the interdependent nature of the Seebeck coefficient $(\alpha)$, electrical resistivity $(\rho)$, and thermal conductivity $(\kappa)$ through the free carrier concentration $(n){ }^{1}$ Several promising classes of materials ${ }^{1}$ have been recently identified for thermoelectrics. These include oxides and Zintl phases and materials with complex crystal structures (e.g., clathrates and zinc antimonides) or nanoscale microstructures $^{2}$ (nanowires, superlattices, or bulk nanostructures). Zintl phases, in particular, have several features that make them ideal candidates for thermoelectric materials, ${ }^{3}$ this has lead to the discovery of the high efficiency $p$-type material $\mathrm{Yb}_{14} \mathrm{MnSb}_{11}$.

$\mathrm{Yb}_{14} \mathrm{MnSb}_{11}$ has a peak $z T$ of $\sim 1.0$ at $1223 \mathrm{~K}$, which is a significant gain over the state-of-the-art $\mathrm{Si}_{0.8} \mathrm{Ge}_{0.2}$ (peak $z T$ $0.6)$ thermoelectric material utilized by NASA in radioisotope generators for deep space probes. ${ }^{4,5} \mathrm{Yb}_{14} \mathrm{MnSb}_{11}$ belongs to a class of compounds of type $A_{14} M P n_{11}$, where $A$ is a heavier alkaline earth or $2+$ rare earth element $\left(\mathrm{Ca}^{2+}, \mathrm{Sr}^{2+}, \mathrm{Ba}^{2+}, \mathrm{Yb}^{2+}, \mathrm{Eu}^{2+}\right), M$ is a group 13 element or transition metal $\left(\mathrm{Al}^{3+}, \mathrm{Mn}^{2+}, \mathrm{Zn}^{2+}\right)$, and $P n$ is a group 15 element (P, As, Sb, Bi). ${ }^{6}$ Zintl-Klemm formalism is used to determine valence. ${ }^{7}$ Group 13 containing compositions (e.g., $\left.\mathrm{Ca}_{14} \mathrm{AlSb}_{11}\right)$ form diamagnetic semiconductors. In contrast, $\mathrm{Yb}_{14} \mathrm{MnSb}_{11}$ is a $p$-type metal with $n=1.3 \times 10^{21} \mathrm{~cm}^{-3}$, corresponding to one hole per $\mathrm{Mn}^{2+}$.

Our prior work with the $\mathrm{Yb}_{14} \mathrm{Mn}_{1-x} \mathrm{Al}_{x} \mathrm{Sb}_{11}$ solid solution found $n$ to linearly follow the manganese concentration (e.g., substitution of $\mathrm{Al}^{3+}$ for $\mathrm{Mn}^{2+}$ decreases $\left.n\right) .{ }^{9}$ The optimum range for $n$ was found to be (4-7) $\times 10^{20} \mathrm{~cm}^{-3}$, which gave a $30 \%$ enhancement in $z T(1.3$ at $1223 \mathrm{~K})$ when compared to the original $\mathrm{Yb}_{14} \mathrm{MnSb}_{11}$ compound. A particularly

${ }^{\text {a)} E l e c t r o n i c ~ m a i l: ~ j s n y d e r @ c a l t e c h . e d u . ~}$ appealing feature of this solid solution is that $n$ can be adjusted without altering the band gap or effective mass, which indicates that the material can be understood with a rigid, parabolic band model.

Unlike the $\mathrm{Yb}_{14} \mathrm{Mn}_{1-x} \mathrm{Al}_{x} \mathrm{Sb}_{11}$ solid solution, substitution of $\mathrm{Mn}^{2+}$ with isoelectronic $\mathrm{Zn}^{2+}\left(\mathrm{Yb}_{14} \mathrm{Mn}_{1-x} \mathrm{Zn}_{x} \mathrm{Sb}_{11}\right)$ does not lead to a continuous alloy. ${ }^{10}$ For $x_{\mathrm{Zn}} \leqslant 0.7$, substitution with isoelectronic $d^{10} \mathrm{Zn}^{2+}$ lowers $\rho$ without altering $n$ or $\alpha$. This decrease in $\rho$ is attributed to the reduction in spin disorder scattering from the coupling of $d^{5} \mathrm{Mn}^{2+}$ and the itinerant hole. The stable phase at high $\mathrm{Zn}$ concentrations has a reduced $\alpha$ attributed to valence fluctuations of $\mathrm{Yb}^{2+/ 3+}{ }^{11}$

Substitution of $\mathrm{La}^{3+}$ for $\mathrm{Yb}^{2+}$ in $\mathrm{Yb}_{14-x} \mathrm{La}_{x} \mathrm{MnSb}_{11}$ should also decrease $n$ linearly with $x$ [up to the solubility limit of $x=0.7$ (Ref. 8)] much like the substitution of $\mathrm{Al}^{3+}$ for $\mathrm{Mn}^{2+}$. In this system, $\mathrm{La}^{3+}$ donates an additional electron, moving the Fermi level closer to the band edge and reduces the hole concentration $n$ by one hole per formula unit (Fig. 1). Sales et al. have measured the low $T$ Hall resistivity and magnetic properties of a single crystal of

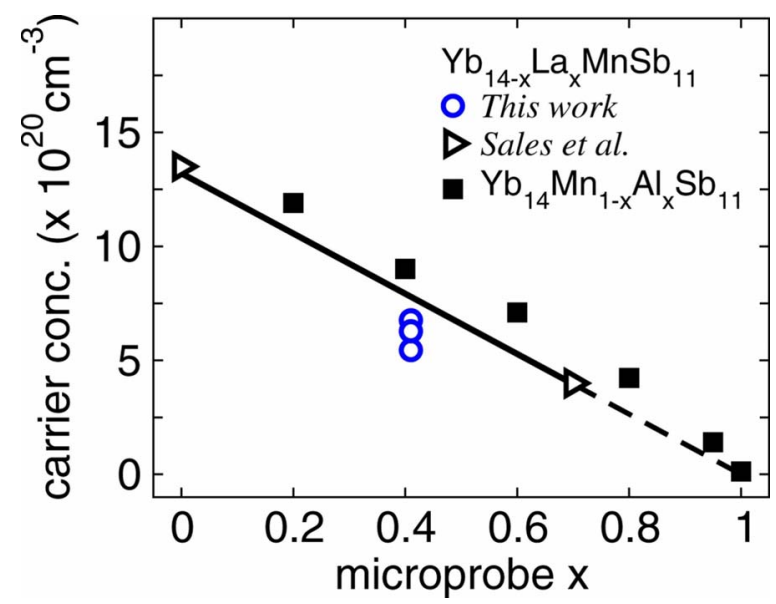

FIG. 1. (Color online) A linear decrease in carrier concentration is expected with increasing $\mathrm{La}^{3+}$ substitution. The measured room temperature carrier concentrations are shown for $\mathrm{Yb}_{13,6} \mathrm{La}_{0.4} \mathrm{MnSb}_{11}$ and prior work by Sales et al. (see Ref. 8). The solid line indicated the reported maximum solubility of La at $x \approx 0.7$. Similar carrier concentration dependence is found for the $\mathrm{Yb}_{14} \mathrm{Mn}_{1-x} \mathrm{Al}_{x} \mathrm{Sb}_{11}$ solid solution (from Ref. 9). 

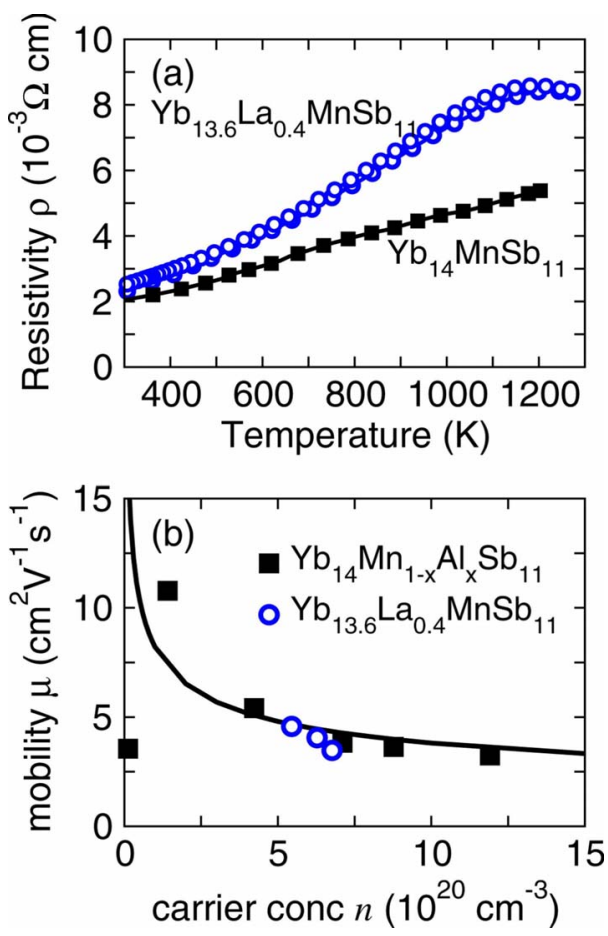

FIG. 2. (Color online) (a) $\mathrm{Yb}_{13.6} \mathrm{La}_{0.4} \mathrm{MnSb}_{11}$ is more resistive than the parent compound $\mathrm{Yb}_{14} \mathrm{MnSb}_{11}$ due to the decreased carrier concentration (both heating and cooling curves are shown). (b) The $\mathrm{Yb}_{13.6} \mathrm{La}_{0.4} \mathrm{MnSb}_{11}$ mobility (for all the samples measured) at $300 \mathrm{~K}$ agrees with the previously observed trend in mobility with carrier concentration for the $\mathrm{Yb}_{14} \mathrm{Mn}_{1-x} \mathrm{Al}_{x} \mathrm{Sb}_{11}$ solid solution (from Ref. 9).

$\mathrm{Yb}_{13.3} \mathrm{La}_{0.7} \mathrm{MnSb}_{11}{ }^{8}$ The reported $n=4 \times 10^{20} \mathrm{~cm}^{-3}$ for $\mathrm{Yb}_{13.3} \mathrm{La}_{0.7} \mathrm{MnSb}_{11}$ is consistent with this simple electron counting approach.

In this work, we investigate the high $T$ thermoelectric properties of $\mathrm{Yb}_{13.6} \mathrm{La}_{0.4} \mathrm{MnSb}_{11}$. Our prior work on the $\mathrm{Yb}_{14} \mathrm{Mn}_{1-x} \mathrm{Al}_{x} \mathrm{Sb}_{11}$ (Ref. 9) enabled us to target the La content that should give the highest $z T$ (by tuning $n$ ) in the range $x=0.6 \pm 0.2$. Crystals were prepared by the Sn-flux method as described in Ref. 4 with a Yb:La ratio of 13:1. The products were analyzed by x-ray diffraction and microprobe analysis to verify purity before pulverizing and hot pressing. The resulting ingot was sliced and three separate samples were characterized to $1273 \mathrm{~K}$. The composition of the pellet was determined by microprobe analysis to be primarily $\mathrm{Yb}_{13.6} \mathrm{La}_{0.4} \mathrm{MnSb}_{11}$, with a secondary phase $(51.5 \mathrm{Yb}: 1.6$ $\mathrm{La} 2.2 \mathrm{Mn}: 44.7 \mathrm{Sb}$ ) that is likely one of the $\mathrm{Yb}-\mathrm{Sb}$ binary phases. Full $\alpha$ and $\rho$ versus $T$ curves were measured on all three samples with nearly identical results.

Room temperature Hall resistance $\left(R_{H}\right)$ measurements of $\mathrm{Yb}_{13.6} \mathrm{La}_{0.4} \mathrm{MnSb}_{11}$ yield $n=1 / R_{H} e=6 \times 10^{20} \mathrm{~cm}^{-3}$. This value is in good agreement with the expected $n$ from the $x$ revealed in the microprobe measurements (Fig. 1) and is within the $n=(4-7) \times 10^{20} \mathrm{~cm}^{-3}$ window expected for high $z T$ from $\mathrm{Yb}_{14} \mathrm{Mn}_{1-x} \mathrm{Al}_{x} \mathrm{Sb}_{11}{ }^{9}$ Figure 2(a) shows that $\rho$ for $\mathrm{Yb}_{13.6} \mathrm{La}_{0.4} \mathrm{MnSb}_{11}$ (one representative sample) increases like a metal or heavily doped semiconductor with increasing $T$ up to $1100 \mathrm{~K}$ due to its constant $n$ and decreasing mobility, $\mu$ $=1 /$ ne $\rho$ (proportional to $\left.T^{-1}\right)$. Above $1100 \mathrm{~K}$, the decrease in $\rho$ is attributed to thermal excitation of carriers across the band gap.

In the $\mathrm{Yb}_{14} \mathrm{Mn}_{1-x} \mathrm{Al}_{x} \mathrm{Sb}_{11}$ system, $\mu$ was found to be dominated by acoustic phonon scattering, with an approxi-
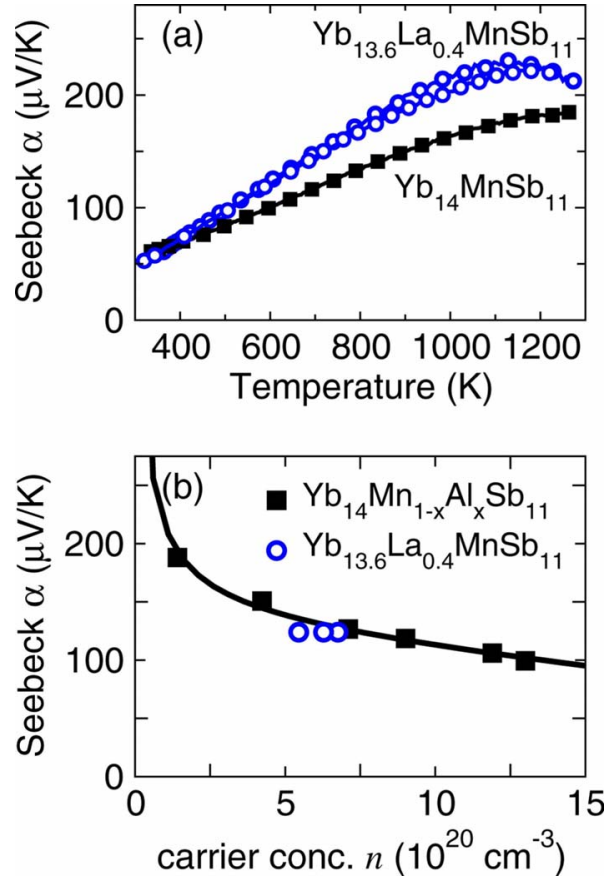

FIG. 3. (Color online) (a) The reduction in carrier concentration for $\mathrm{Yb}_{13.6} \mathrm{La}_{0.4} \mathrm{MnSb}_{11}$ compared to the parent compound $\mathrm{Yb}_{14} \mathrm{MnSb}_{11}$ leads to an increased Seebeck coefficient (both heating and cooling curves are shown). (b) The $\mathrm{Yb}_{13,6} \mathrm{La}_{0.4} \mathrm{MnSb}_{11}$ Seebeck coefficient at $600 \mathrm{~K}$ fits the trend previously found for the $\mathrm{Yb}_{14} \mathrm{Mn}_{1-x} \mathrm{Al}_{x} \mathrm{Sb}_{11}$ solid solution (from Ref. 9).

mately $n^{-1 / 3}$ dependence. ${ }^{9}$ Likewise, for $\mathrm{Yb}_{13.6} \mathrm{La}_{0.4} \mathrm{MnSb}_{11}$ we find that decreasing $n$ leads to an increased $\mu$ $\left(4.3 \mathrm{~cm}^{2} \mathrm{~V}^{-2} \mathrm{~s}^{-1}\right.$ at $\left.300 \mathrm{~K}\right)$. Figure 2(b) superimposes the room temperature $\mu$ for $\mathrm{Yb}_{14} \mathrm{Mn}_{1-x} \mathrm{Al}_{x} \mathrm{Sb}_{11}$ and the three samples of $\mathrm{Yb}_{13.6} \mathrm{La}_{0.4} \mathrm{MnSb}_{11}$, with a $n^{-1 / 3}$ fit. The agreement in $\mu$ between the different alloys in Fig. 2(b) suggests that (a) $\mu$ is determined primarily by $n$ and (b) $\mu$ at the same $n$ are approximately equal. This second point is interesting, as the scattering mechanisms are different between $\mathrm{Yb}_{13.6} \mathrm{La}_{0.4} \mathrm{MnSb}_{11}$ and $\mathrm{Yb}_{14} \mathrm{Mn}_{1-x} \mathrm{Al}_{x} \mathrm{Sb}_{11}$ even with the same $n$. $\mathrm{Yb}_{1-x} \mathrm{La}_{x} \mathrm{MnSb}_{11}$ will exhibit more spin disorder scattering than $\mathrm{Yb}_{14} \mathrm{Mn}_{1-x} \mathrm{Al}_{x} \mathrm{Sb}_{11}$ because of the greater content of magnetic $\mathrm{Mn}^{2+}$ compared to nonmagnetic $\mathrm{Al}^{3+}$ ( $\mathrm{Yb}$ and $\mathrm{La}$ are nonmagnetic, with $\mathrm{Yb}$ expected to be all 2 + and $\mathrm{La}, 3+$ for this compound). The spin disorder scattering has been found to induce a $T$ independent term in $\rho$ that can be reduced ${ }^{10}$ with doping of nonmagnetic $\mathrm{Zn}^{2+}$. Similarly, the charge difference of $\mathrm{Al}^{3+}$ compared to $\mathrm{Mn}^{2+}$ will contribute impurity scattering that may also be $T$ independent. The charge disorder from having $\mathrm{La}$ on the $\mathrm{Yb}$ site is expected to have little effect on the conduction because the bands comprising the mobile holes should be mostly $\mathrm{Sb}$ and transition metal character with very little rare earth $(\mathrm{Yb}, \mathrm{La})$ character. ${ }^{12}$ The similarity of $\mu$ for $\mathrm{Yb}_{13.6} \mathrm{La}_{0.4} \mathrm{MnSb}_{11}$ and $\mathrm{Yb}_{14} \mathrm{Mn}_{0.4} \mathrm{Al}_{0.6} \mathrm{Sb}_{11}$ (with the same $n$ ) suggests that the spin disorder and impurity scattering may be of similar orders of magnitude.

Figure 3(a) shows that $\alpha$ for $\mathrm{Yb}_{14} \mathrm{MnSb}_{11}$ and $\mathrm{Yb}_{13.6} \mathrm{La}_{0.4} \mathrm{MnSb}_{11}$ (one representative sample) increases linearly with increasing $T$ through the extrinsic regime (up to about $1100 \mathrm{~K}$ ). At high $T$, the thermal excitation of electrons and holes leads to a compensated, reduced $\alpha$, which is more noticeable in the lower $n$ material. The peak in $\alpha$ may be 


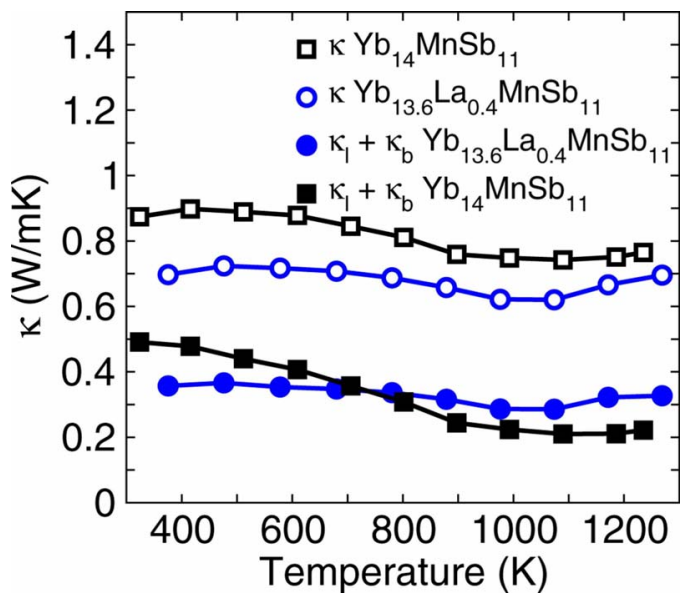

FIG. 4. (Color online) Thermal conductivity from flash diffusivity measurements for $\mathrm{Yb}_{13.6} \mathrm{La}_{0.4} \mathrm{MnSb}_{11}$ and $\mathrm{Yb}_{14} \mathrm{MnSb}_{11}$. The electronic component may be subtracted (Wiedemann-Franz law) to leave the lattice $\left(\kappa_{l}\right)$ and bipolar $\left(\kappa_{b}\right)$ components of the thermal conductivity.

used to estimate the band gap $\left(E_{g}=2 e \alpha_{\max } T_{\max }\right)$ (Ref. 13) to be $0.5 \mathrm{eV}$, a value identical to that found across the $\mathrm{Yb}_{14} \mathrm{Mn}_{1-x} \mathrm{Al}_{x} \mathrm{Sb}_{11}$ solid solution. Superimposing $\alpha$ for $\mathrm{Yb}_{14} \mathrm{Mn}_{1-x} \mathrm{Al}_{x} \mathrm{Sb}_{11}$ at $600 \mathrm{~K}$ with the values obtained for $\mathrm{Yb}_{13.6} \mathrm{La}_{0.4} \mathrm{MnSb}_{11}$ reveals the La-doped samples fit the $\mathrm{Mn}-\mathrm{Al}$ trend with $n$. The $\mathrm{Yb}_{14} \mathrm{Mn}_{1-x} \mathrm{Al}_{x} \mathrm{Sb}_{11}$ solid solution was found to behave as a degenerate semiconductor with energy independent scattering, resulting in $\alpha$ proportional to $T n^{-2 / 3}$ [Eq. (1)]. At the low $T$, degenerate limit, Eq. (1) can be used to calculate the effective mass $\left(m^{*}\right)$ from $n$ and the slope of $\alpha$ versus $T$ plot. For $\mathrm{Yb}_{13.6} \mathrm{La}_{0.4} \mathrm{MnSb}_{11}$ the effective mass was found to be $\sim 2.7 m_{e}$, similar to the relatively constant value of $\sim 3 m_{\mathrm{e}}$ found for $\mathrm{Yb}_{14} \mathrm{Mn}_{1-x} \mathrm{Al}_{x} \mathrm{Sb}_{11}$. The similar properties between the $\mathrm{La}^{3+}$ and $\mathrm{Al}^{3+}$ doped systems indicate that the band structure is minimally altered by doping either the cation or the transition metal site; doping simply shifts the Fermi energy within a single parabolic band,

$$
\alpha=\frac{8 \pi^{2} k_{B}^{2}}{3 e h^{2}} m^{*} T\left(\frac{\pi}{3 n}\right)^{2 / 3} .
$$

The $\kappa=D d C_{p}$ (Fig. 4) was calculated from laser flash thermal diffusivity $(D)$ measurements, measured density $(d)$, and heat capacity $\left(C_{p}\right)$ estimated using the method of Dulong-Petit. The Dulong-Petit method is consistent with prior studies on the high $T$ properties of $\mathrm{Yb}_{14} \mathrm{MnSb}_{11}$ and its alloys but is expected to be an underestimation of $C_{p}$. To determine the effect of alloying on the lattice thermal conductivity $\left(\kappa_{l}\right)$, the electronic component $\left(\kappa_{e}\right)$ was subtracted from $\kappa$ using the Wiedemann-Franz law $\left(\kappa_{e}=L T / \rho ; \kappa=\kappa_{l}\right.$ $+\kappa_{e}+\kappa_{b}$; where $L$ is the Lorenz factor. The remainder, $\kappa_{l}$ $+\kappa_{b}$, (Fig. 4) has a minimum value of $\sim 0.3 \mathrm{~W} / \mathrm{m} \mathrm{K}$. As seen in the $\mathrm{Yb}_{14} \mathrm{Mn}_{1-x} \mathrm{Al}_{x} \mathrm{Sb}_{11}$ solid solution, the rise in $\kappa_{l}+\kappa_{b}$ at high $T$ is due to the excitation of mixed carriers enhancing the bipolar $\left(\kappa_{b}\right)$ term. ${ }^{14}$

Figure 5 shows the $z T$ of the parent compound, $\mathrm{Yb}_{14} \mathrm{MnSb}_{11}$, and $\mathrm{Yb}_{13.6} \mathrm{La}_{0.4} \mathrm{MnSb}_{11}$, with a peak $z T$ of 1.15 at $1150 \mathrm{~K}$ for the alloy. The magnitude of $z T$ is lower than the equivalent $n$ sample from the $\mathrm{Yb}_{14} \mathrm{Mn}_{1-x} \mathrm{Al}_{x} \mathrm{Sb}_{11}$ solid

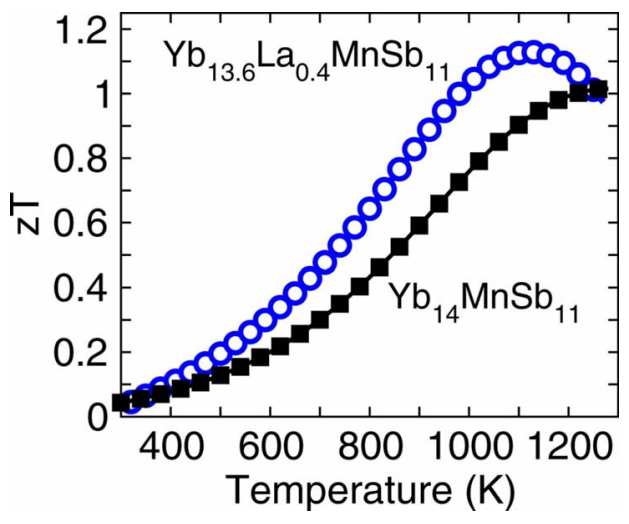

FIG. 5. (Color online) Thermoelectric figure of merit $(z T)$ for $\mathrm{Yb}_{13.6} \mathrm{La}_{0.4} \mathrm{MnSb}_{11}$ and the parent compound $\mathrm{Yb}_{14} \mathrm{MnSb}_{11}$ (from Ref. 4).

solution $\left(\mathrm{Yb}_{14} \mathrm{Mn}_{0.4} \mathrm{Al}_{0.6} \mathrm{Sb}_{11} 1.28\right.$ at $\left.1200 \mathrm{~K}\right)$. This difference is due to $\sim 3 \%$ differences in $\alpha$ and $\kappa$ but well within the expected uncertainty in these high $T$ measurements. Greater (or different) La content may produce higher $z T$ than the composition studied here. However we expect the improvement to be minimal based on the broad maximum in $z T$ found for $\mathrm{Yb}_{14} \mathrm{Mn}_{1-x} \mathrm{Al}_{x} \mathrm{Sb}_{11}$.

Alloying $\mathrm{Yb}_{14} \mathrm{MnSb}_{11}$ on the rare earth site with $\mathrm{La}^{3+}$ permits the optimization of $n$ and $z T$ in a manner similar to $\mathrm{Al}^{3+}$ substitution on the transition metal site. For both the Laand Al-doped systems, the same simple rigid parabolic band model explains the behavior of the high $T$ transport properties. The development of two separate dopant sites permits the partial decoupling of $n$, spin disorder scattering, and impurity scattering. Such control should lead to further improvements in $z T$ through simultaneous doping of different elements on both sites.

We thank NASA/JPL, the Beckman Foundation, and NSF (Contract No. DMR-0600742) for funding and B. C. Sales for useful discussions.

${ }^{1}$ G. J. Snyder and E. S. Toberer, Nat. Mater. 7, 105 (2008).

${ }^{2}$ H. Böttner, G. Chen, and R. Venkatasubramanian, MRS Bull. 31, 211 (2006)

${ }^{3}$ S. M. Kauzlarich, S. R. Brown, and G. J. Snyder, Dalton Trans. 7, 2099 (2007).

${ }^{4}$ S. R. Brown, S. M. Kauzlarich, F. Gascoin, and G. J. Snyder, Chem. Mater. 18, 1873 (2006).

${ }^{5}$ C. B. Vining, W. Laskow, J. O. Hanson, R. R. Van der Beck, and P. D. Gorsuch, J. Appl. Phys. 69, 4333 (1991).

${ }^{6}$ G. Cordier, H. Schäfer, and M. Stelter, Z. Anorg. Allg. Chem. 519, 183 (1984); Julia Y. Chan, Marilyn M. Olmstead, Susan M. Kauzlarich, and D. J. Webb, Chem. Mater. 10, 3583 (1998).

${ }^{7}$ S. M. Kauzlarich, Chemistry, Structure and Bonding of Zintl Phases and Ions (VCH, New York, 1996).

${ }^{8}$ B. C. Sales, P. Khalifah, T. P. Enck, E. J. Nagler, R. E. Sykora, R. Jin, and D. Mandrus, Phys. Rev. B 72, 205207 (2005).

${ }^{9}$ E. S. Toberer, C. A. Cox, S. R. Brown, T. Ikeda, A. F. May, S. M. Kauzlarich, and G. J. Snyder, Adv. Funct. Mater. (in press).

${ }^{10}$ S. R. Brown, E. S. Toberer, T. Ikeda, C. A. Cox, F. Gascoin, S. M. Kauzlarich, and Chem. Mater. 20, 3412 (2008).

${ }^{11}$ I. R. Fisher, S. L. Bud'ko, C. Song, P. C. Canfield, T. C. Ozawa, and S. M. Kauzlarich, Phys. Rev. Lett. 85, 1120 (2000).

${ }^{12}$ D. Sanchez-Portal, R. M. Martin, S. M. Kauzlarich, and W. E. Pickett, Phys. Rev. B 65, 144414 (2002).

${ }^{13}$ H. J. Goldsmid and J. W. Sharp, J. Electron. Mater. 28, 869 (1999).

${ }^{14}$ H. J. Goldsmid, Applications of Thermoelectricity (Wiley, London, 1960). 